\title{
PRODUCCIÓN EDITORIAL DESDE UNA MIRADA TRANSMEDIÁTICA
}

\section{EDITORIAL PRODUCTION FROM A TRANSMEDIA PERSPECTIVE}

\section{PRODUCĢ̃̃o EDITORIAL DESDE UMA MIRADA TRANSMEDIÍTICA}

\section{Páginas Jairo Antonio Pérez Rubio \\ 10-21 jairoantonioperez@gmail.com}

Recibido Doctor en educación de la Universidad Pedagógica Nacional.

13 de mayo 2016

Experto en temas de cibercultura.

\section{Aceptado}

15 junio de 2016 
Resumen

El texto es un resultado parcial de la investigación que se adelanta en la Universidad Sergio Arboleda titulada Experiencias transmediáticas en el desarrollo de competencias comunicativas, la cual parte de la premisa de que la transmedia contribuye al desarrollo de las competencias comunicativas de los estudiantes y se lleva a cabo bajo la combinación de dos rutas metodológicas: el paradigma holístico y el totalizante. Este artículo se inscribe en esta investigación a partir de la pregunta sobre la relación entre el mundo editorial y la cibercultura, como un horizonte del lenguaje transmedial.

Para ese efecto, en el texto se revisan, en primer lugar, los elementos básicos que describen la mentada relación entre el mundo editorial y la cultura digital; en segundo lugar, se analizan, en particular, las narrativas digitales; y, por último, se presentan unas conclusiones.

Palabras clave Transmedia, competencias comunicativas, mundo editorial, cultura digital 


\section{Abstract}

This document is a partial research outcome that takes place at Universidad Sergio Arboleda, the research is entitled Transmedia Experiences in the Development of Communicative Competences. The hypothesis states that transmedia contributes to the development of students' communicative skills. The research is carried away by following two methodological approaches: the holistic paradigm and the total paradigm. The present article inscribes in the research by wondering about the relationship between cyber culture and the editorial field both as a frame for transmedia language. To do so, first, the basic elements that describe the above mentioned relationship are reviewed; second, digital narratives, in particular, are analyzed, and, finally, conclusions are drawn.

\section{Key words}

Transmedia, Communicative Skills, Editorial Field, Digital Culture

\section{Resumo}

O texto é um resultado parcial da investigação que se adianta na Universidad Sergio Arboleda titulado Experiências transmediáticas no desenvolvimento de competências comunicativas, a qual parte da premisa de que a transmedia contribui ao desenvolvimento das competências comunicativas dos estudantes leva-se a cabo baixo a combinação de duas rotas metodológicas: o paradigma holístico e o totalizante. Este artigo inscreve-se nesta investigação a partir da questão sobre a relação entre o mundo editorial e a cibercultura, como um horizonte da linguagem transmedial. Para esse efeito, no texto revisam-se, em primeiro lugar, os elementos básicos que descrevem a mentada relação entre o mundo editorial e a cultura digital; em segundo lugar, analisam-se, em particular, as narrativas digitais; e, por último, apresentam-se umas conclusões.

\section{Palavras-chave}

Transmedia, competências comunicativas, mundo editorial, cultura digital 


\section{Introducción}

El tema de la producción editorial en el contexto de la cibercultura no se refiere únicamente a las Tecnologías de la Información y Comunicación —-Tic-, sino también a los procesos comunicativos que se producen a través de tecnologías digitales. La era digital está cambiando las formas y maneras de interrelacionarse, están apareciendo códigos sociales para comunicarse y formas distintas de hacer negocios, de generar relaciones afectivas, de enseñar y aprender y de circular la producción intelectual de contenidos diferentes a los tradicionales. Observar cómo suceden estos acontecimientos a través del ciberespacio o de cualquier dispositivo digital es una de las motivaciones que tengo para aportar algunas ideas al campo editorial.

En los últimos años una gran cantidad de información parece inundar el mundo de las telecomunicaciones, en los mensajes de texto del teléfono celular, en los correos electrónicos, en los tuits y en las actualizaciones de estado de nuestros amigos en el Facebook, en los titulares que atraviesan nuestras pantallas de televisión o en las páginas de inicio de Google. A principios de 2014 ya había doscientos millones de tuits al día vía Twitter, la red social en la que la gente puede enviar mensajes de hasta 140 caracteres a sus seguidores. Más de ochocientos millones de veces a la semana, grupos de amigos comparten enlaces de videos, historias, artículos y páginas web. Lo mismo ha sucedido con Facebook, un servicio originalmente orientado a estudiantes, que en los últimos años ha añadido millones de usuarios de todas las edades temerosos de perderse este fenómeno tecnológico.

Crear una cultura digital en el campo editorial, en el contexto académico, es bastante plausible. Una manera de hacerlo es abordar las tecnologías digitales de manera transmediática, otro modo es verlas sólo como herramientas y dispositivos. Estas alternativas hacen pensar sobre cómo los docentes y estudiantes podemos hacer uso de estas herramientas transmediáticas para entablar una mejor comunicación, una mejor enseñanza, una mejor colaboración en el mundo editorial. Pero uno de los problemas a vencer, a mi modo de ver, es que existen culturas y prácticas académicas muy arraigadas y resistentes al cambio. El miedo al cambio y al ensayo está produciendo una parálisis en las didácticas de algunos profesores y estudiantes.

Las comunicaciones en el siglo xxi han tomado mucha fuerza y han generado narrativas multimediales ${ }^{1}$ y transmediáticas ${ }^{2}$; ahora percibimos una comu-

1 El término multimedial lo interpretamos como la posibilidad de un medio para contener audio, video, texto, imágenes, símbolos, signos y emoticones por ejemplo para transmitir un contenido. Internet sería el ejemplo más evidente de un medio multimedial.

2 Entendemos por transmediáticas un fenómeno de narrativas que se expanden a través de medios y plataformas, consiste en transitar un relato por diferentes medios digitales y análogos. 
nicación mucho más colectiva, interactiva, participativa y audiovisual. Este desarrollo dentro de las comunicaciones también se ha logrado por la apertura de espacios cada vez más personalizados en la red de redes, lo que podría ser consecuencia del hecho de que somos seres que comunicamos a través de símbolos y signos, pero, sobre todo, somos texto, audio e imagen.

Las $\mathrm{TIC}^{3}$, TEP, TAC, la construcción de redes sociales, los dispositivos móviles, el uso de las wikis y los blogs, la inteligencia artificial, la computación en la nube, el internet, entre muchas otras cosas, son las más recientes e importantes ideas en cuanto a participación dentro de la era del conocimiento, la sociedad red. Los nuevos paradigmas dentro de las comunicaciones y la transformación en la manera como nos relacionamos, en la forma en que producimos, consumimos, remezclamos, compartimos y distribuimos contenidos de manera multimedial y multimodal, han hecho que el mundo ya no se vea ni se aprenda igual que hace tan sólo cinco años.

\section{El mundo editorial en la cultura de la sociedad digital}

La cultura de internet es la cultura de los creadores y usuarios de internet. En este orden de ideas interpretamos la cultura como un conjunto de valores y creencias que conforman el comportamiento. Los

Es lo que Henry Jenkins denominó transmedia storytelling. Los usuarios participan en esta expansión de los relatos mediante sus propios contenidos, los cuales se difunden y comparten por medio de las redes sociales.

3 Dolors Reig Hernández en su blog El Caparazón nos comenta que una manera de profundizar en la cuestión de cómo se comportan los jóvenes en el nuevo ecosistema es, tal y como hicieron desde la Fundación Mc Arthur durante tres años hasta el 2008 en un conocido estudio etnográfico - Living and Learning with new media-, simplemente observarlos. Las conclusiones presentaban lo que ellos llamaban las tres formas básicas de participación en los nuevos medios y podrían entenderse también como la evolución del uso o apropiación de las tecnologías si las ponemos en relación con la clasificación TIC, TAC, TEP - Tecnologías de la información y la comunicación, Tecnologías de la aprendizaje y el conocimiento y Tecnologías del empoderamiento y la participación- (Reig, 2011). esquemas de comportamiento repetitivos generan costumbres que se imponen mediante las instituciones y las organizaciones sociales formales. Castells (2002) lo expresa de esta manera: «[...] si bien se manifiesta de forma explícita, la cultura es una construcción colectiva que trasciende a las preferencias individuales e influye en las actividades de las personas pertenecientes a dicha cultura, en este caso, los usuarios/productores de Internet» (p. 51).

Por su parte, el filósofo de la cultura digital Pierre Lévy (2007) nos presenta su interpretación de lo que para él significa cultura: «[...] la cultura es un complejo de redes de sistemas culturales entramados entre sí, es decir, que se solapan, comparten agentes, entornos y recursos culturales, interaccionan, se comunican y se transforman mutuamente» (p. 9). Este autor utiliza los términos cultura digital o cultura de la sociedad digital para referirse a la cultura propia de las sociedades en las que las tecnologías digitales configuran las formas dominantes de la información, comunicación y conocimiento. Para él, la cultura digital está entendida como «[...] la totalidad de las redes de sistemas socio-técnico culturales que han surgido y han sido configurados por los impactos de las nuevas tic - tecnologías de la información y comunicación—» (p. 10).

Dado lo anterior, en los últimos años hemos estado hablando de convergencia cultural, convergencia mediática que se produce en la interacción de los sujetos a través de medios y plataformas. De acuerdo con Jenkins (2006), el consumo se ha convertido en un proceso colectivo, y a eso se refiere cuando hablamos de inteligencia colectiva, un término acuñado por Pierre Lévy (2004): «Ninguno de nosotros puede saberlo todo; cada uno de nosotros sabe algo, todo conocimiento reside en la humanidad» (p. 36). Jenkins (2006) sostiene que la convergencia mediática es más que un simple cambio tecnológico:

La convergencia altera la relación entre las tecnologías existentes, las industrias, los mercados, los géneros, y el público. La 
convergencia altera la lógica con la que operan las industrias mediáticas y con la que procesan la información y el entretenimiento Las tecnologías mediáticas han hecho posible que el mismo contenido fluya por canales muy diferentes y asuma formas muy diversas en el punto de recepción. (p. 26).

En el contexto de la cibercultura, a nivel de la producción de contenidos no hay una clara distinción entre autores y lectores, productores y espectadores, creadores e intérpretes. Aparece un nuevo tipo de usuario en la red, al que autores como Toffler ${ }^{4}$ denominan "prosumidor», acrónimo de productor y consumidor. Se trataría de usuarios familiarizados con el manejo de las nuevas tecnologías en general y de internet y las redes sociales en particular, que asumen un rol activo e impulsan un flujo multidireccional de las informaciones.

Hoy en día los profesores, en muchos casos considerados emigrantes digitales, nos encontramos con unas generaciones que han nacido inmersas en la tecnología digital, son generaciones rodeadas por el uso de computadoras, juegos de video, música digital, videos, teléfonos celulares y otros juguetes, en fin, por el uso de dispositivos digitales, que no son otra cosa que artefactos tecnológicos. Tales medios son utilizados no sólo para aprender sino para socializar, para generar contenidos, por lo que algunos autores llaman a sus usuarios Nativos digitales

\footnotetext{
4 La palabra prosumidor, en inglés, prosumer, es un acrónimo que procede de la fusión de dos palabras: «producer» productor-y «consumer» - consumidor-. El concepto fue anticipado por Marshall McLuhan y Barrington Nevitt, quienes en el libro Take Today (1972) afirmaron que la tecnología electrónica permitiría al consumidor asumir simultáneamente los roles de productor y consumidor de contenidos. McLuhan infería que en la edad posteléctrica los actores comunicativos resentirían profundas transformaciones resultantes de la complejidad inherente a los nuevos ambientes comunicativos. El concepto «prosumidor» tiene particular relevancia en la «ecología de medios». Alvin Toffler introdujo formalmente el término prosumidor, en 1980, en el libro «La tercera ola». El capítulo XX del libro referido precisamente consigna el siguiente título: «El resurgimiento del prosumidor».
}

(Piscitelli, 2009; Prensky, 2008) $^{5}$. Son jóvenes a los que les encanta hacer varias cosas al mismo tiempo, muchos de ellos son multitareas y, en algunos casos, multimediales. Prefieren el universo gráfico al textual. Eligen el acceso aleatorio e hipertextual a la información en vez del lineal, propio de la secuencialidad, el libro y la era analógica. En síntesis, la manera en que los menores de 20 años experimentan el mundo hoy en día es diferente; Morduchowicz (2008) lo plantea de la siguiente manera: "Los jóvenes, cuyas identidades se trazan en la intersección del texto escrito, la imagen electrónica y la cultura popular, viven una experiencia cultural distinta, que incluye nuevas maneras de percibir, de sentir, de escuchar y de ver» (p. 25).

Sumado a lo anterior, muchas revistas científicas ya no se imprimen en papel, sino que se encuentran en formato digital, con ayudas interactivas, hipertextualizadas, con gráficas dinámicas elaboradas en 3D, las cuales se distribuyen a miles de usuarios por internet; igual situación pasa con miles de publicaciones de diferente índole.

Los libros impresos, atravesados por aspectos económicos, sociales, tecnológicos, etc., están pasando de ser un objeto editorial a ser un objeto cultural, y es ahí donde sería interesante formar editores transmediáticos que respondan a las necesidades de los nativos digitales. La discusión de si en el futuro los libros impresos van a desaparecer pasa

5 ¿Cómo debemos llamar a estos «nuevos» estudiantes de hoy? ¿En Red o D-GEN, por Generación Digital? Algunos los refieren como N-GEN, por su generación, y en cuanto Nativos digitales. Los jóvenes son hoy todos «nativos» de la lengua digital de juegos por computadora, video e internet. ¿Y el resto de nosotros?

Nosotros, los que no nacimos en el mundo digital, pero tenemos algún punto de nuestras vidas cerca y adaptada a la mayoría de aspectos de la nueva tecnología, somos Inmigrantes Digitales. La importancia de la distinción es que, como inmigrantes digitales, aprendemos — algunos más que otros—a adaptarnos al ambiente, y conservamos siempre una cierta conexión con el «mundo anterior» - la llamo «acento»: sostenemos un pie en el pasado-. El acento del «inmigrante digital» se puede encontrar en cosas tales como navegar en internet, en primer lugar, y obtener información, en segundo término; o leer manuales de un programa para utilizarlo después. La gente más vieja «socializa» de manera diferente con sus hijos, ahora están en el proceso de aprender una nueva lengua. 
a un segundo plano, ahora pensamos que el libro interactivo, multimedial y transmediático no sólo estimula la imaginación, sino que proporciona experiencias inmersivas. Estas perspectivas nos plantean el reto de formar editores que entiendan las nuevas lógicas de creación y distribución de contenidos editoriales en el mundo del ciberespacio.

En contraposición a la frase de Marshall McLuhan «el medio es el mensaje», yo diría, desde una mirada transmediática, que «el mensaje demanda el medio hoy en dia", y esto va por la misma vía de lo planteado por Jenkins (2006) cuando dice: «Dejemos que cada medio haga lo mejor que sabe hacer».

Otro mito que considero se debe ir desmontando es el de pensar que la hiperconectividad digital de los jóvenes los hace menos capaces en otras tareas y, a su vez, seres más aislados. En relevantes estudios, como el de Living and Learning with New Media (Ito et al., 2008), se concluye que el tiempo online es bueno para los menores (Shiels 2008). Ya no es una pérdida de tiempo la navegación por internet, jugar digitalmente o el paso por las redes sociales; los jóvenes están asimilando competencias tecnológicas y comunicativas necesarias para el mundo contemporáneo. Además, no sólo están integrándose en procesos comunicativos online, sino que comienzan a tener conciencia clara de la importancia de nuestras identidades públicas. Incluso de estudios tan difundidos como el de Pew Internet ${ }^{6}$ se podrían

\footnotetext{
6 Pew Internet \& American Life Project. Generations Online in 2010, overview (Hernández-Pérez, 2010). Los informes Pew son muy citados por los medios de comunicación de todo el mundo. Suelen ser informes, bastante rigurosos, realizados por el Pew Reserch Center - PRC-, una especie de organización no gubernamental, políticamente independiente, que proporciona e interpreta datos obtenidos a través de encuestas y sondeos, realizados principalmente en Estados Unidos. El informe Generations online in 2010, publicado en diciembre de 2010, es fruto del Pew Internet \& American Life Project. Entre los objetivos de este proyecto está proporcionar información sobre el impacto de internet en los niños, las familias, las comunidades, los lugares de trabajo, las escuelas, la salud, la vida civil y la política. Este informe es una continuación de otros estudios anteriores realizados con el fin de analizar el uso que hacen de internet los usuarios en función de su edad, de la generación a la que pertenecen.
}

sacar conclusiones, como la de que los menores más conectados presentan mayores destrezas de interacción social en su vida analógica, lo que desmonta en cierto modo la idea del aislamiento social producido por los nuevos entornos comunicativos. «Nos encontramos en un momento en el que el antiguo sistema de medios está muriendo y está naciendo un nuevo sistema» (Jenkins, 2014). Los contenidos en la comunicación tradicional están empezando a tornarse algo rígidos a la hora de compartir cualquier tipo de información. Sin embargo, las nuevas plataformas y los nuevos medios están abriendo paso a la interactividad con el usuario, haciendo una alianza entre viejos y nuevos medios. Desde un principio, las historias han sido controladas por un número pequeño de empresas en las que el lector no tiene participación alguna, así que a partir de la convergencia de medios se abre un nuevo capítulo para los consumidores de contenido e, igualmente, para un escenario de medios mucho más complejo, que algunos autores denominan como ecosistemas mediáticos.

Hasta hace muy poco las grandes propiedades intelectuales estaban hechas para ser exitosas sobre una única plataforma mediática: el libro impreso, pero a medida que la tecnología invade los hogares, las empresas, la academia, la comunicación, esta propiedad intelectual se ha empezado a expandir hasta ocupar cada dispositivo tecnológico y hacer que los usuarios participen en las decisiones de generación de contenidos. Por tanto, se ha vuelto importante la participación del usuario en las decisiones de cualquier producción editorial; no importa si ésta es positiva o negativa, sino que el prosumidor pueda construir contenidos por medio de cualquier medio o cualquier plataforma expandiendo el relato o creando nuevos relatos a partir de la historia original.

Con el auge de las nuevas tecnologías se ha evidenciado una migración de contenido a diferentes plataformas y eso específicamente es lo que ha causado mayor interés de los usuarios por conocer la historia desde diferentes puntos de vista. Lo nuevo 
del término transmedia no es que las historias se propaguen por diferentes plataformas y medios análogos, lo importante del fenómeno transmediático es el desarrollo y la producción de los relatos que van complementándose y expandiéndose por diferentes canales y medios de comunicación.

De acuerdo con lo anterior, considero relevante formar editores transmediáticos que estén en capacidad de entender que una historia transmediática se desarrolla a partir de múltiples plataformas, no repitiendo la misma historia, sino complementándola en cada medio. La idea de lograr esta difusión, ya sea en televisión, videojuegos, cómics, redes sociales o películas, es que los usuarios que no conozcan la historia puedan experimentar y entenderla dependiendo del medio que elijan.

Siguiendo la misma línea argumentativa, uno de los autores más destacados en el género de transmedia es Carlos Alberto Scolari (2013), quien ha seguido paso a paso las investigaciones de Jenkins en su libro Narrativas Transmedia, en el cual expone varios casos exitosos como el de Matrix, Star Wars y Harry Potter. Cada uno de estos fenómenos en el área del entretenimiento ha empezado por el lanzamiento de una película, libro o serie y se ha ido expandiendo hasta llegar a la producción de cómics, cortometrajes o videojuegos:

Las narrativas transmedia son una particular forma narrativa que se expande a través de diferentes sistemas de significación - verbal, icónico, audiovisual, interactivo, etc.- $\mathrm{y}$ medios —cine, cómic, televisión, videojuegos, teatro, etc.- - Las narrativas transmedia no son simplemente una adaptación de un lenguaje a otro: la historia que cuenta el cómic no es la misma que aparece en la pantalla del cine o en la microsuperficie del dispositivo móvil. (Scolari, 2013, p. 47).

Internet está afectando a los intermediarios principalmente en lo que se refiere a la producción intelectual y artística. En el mundo musical las disqueras empiezan a perder protagonismo, los mismos músicos, además de ser creadores, son ahora distribuidores y comercializan su producción. Lo mismo se empieza a notar en el caso de escritores de cualquier género literario: ellos no sólo construyen historias, sino que ya las están recreando mediante el uso de variadas herramientas y aplicaciones digitales, hipermediales, interactivas y participativas.

\section{La narrativa digital como experiencia emergente en la producción editorial}

La narrativa digital constituye hoy un medio expresivo muy potente y diverso que, si bien exige la reconfiguración de los roles tradicionales del escritor y del lector, instaura posibilidades inéditas de interacción y de creación. Asistimos a una gran variedad de expresiones narrativas en un medio que, como el digital, está en constante evolución: desde el simple hipertexto que organiza los enunciados narrativos en estructuras no lineales hasta la construcción de «metaversos» como los que se disponen en las plataformas Active Worlds y Habbo o, más recientemente, Second Life - verdadera realidad virtual en línea-, pasando por los hipermedias narrativos y los videojuegos online (Rodríguez, 2007). Estos ejercicios nos enfrentan a preguntas inquietantes: ¿dónde está la «obra»? ¿En el modelo interactivo que ofrece el artista al usuario? ¿En las interacciones propiamente dichas que podrían llegar a alterar radicalmente la obra «original»? ¿En la idea inicial del autor, quien busca sobre todo promover la interactividad? ¿Quién es finalmente el autor? Asumirlas implica aceptar que estamos ante el surgimiento de expresiones artísticas y estéticas vinculadas al sujeto interconectado de la cibercultura.

En Colombia, aun cuando no existe una dinámica muy marcada hacia la producción de obras narrativas digitales, existen varias experiencias destacables, entre ellas las de tres creadores: Juan Gutiérrez, Carlos Roberto Torres y Jaime Alejandro Rodríguez. Juan Gutiérrez viene experimentando desde mediados de la década de 1990 con la narrativa digital, 
el hipertexto y la literatura digital adaptativa, que se caracteriza por la presencia de un «sistema de información» o "motor de inteligencia artificial» que actúa como "elemento intermediario» entre el autor y el lector. Sus dos obras: Condiciones Extremas (1998) y El primer vuelo de los hermanos Wright (2006), son auténticas producciones pioneras dentro del mundo narrativo y digital en español en Latinoamérica. De su última obra se destaca no sólo la alta calidad del texto narrativo sino las posibilidades que abre para el lector. Al negociar el significado y tratar de ensamblar cada parte de estas narrativas a la narrativa principal, el lector participa de lo que Espen Aarseth ha denominado como proceso «ergódico»: un esfuerzo no trivial que permite al lector transitar por el texto.

De otro lado, caminandobogotá.net (2007), del diseñador Carlos Roberto Torres, es un experimento de creación digital hipermedia —un medio que integra interactivamente imagen, animación y sonido- que recrea la experiencia de un flâneur o transeúnte por las calles de la capital colombiana. Usando creativa y potentemente las posibilidades del medio y eludiendo intencionalmente la escritura, este "relato» sobre Bogotá permite no sólo recorrer las curiosas historias que nos propone el sitio -y que van creciendo en número-, sino que invita al usuario a colaborar con el relato, facilitando la inclusión de fotografías personales de la ciudad. También incluye una sencilla herramienta para construir colectivamente una galería de grafitis digitales y la interacción a través de un blog propio, con lo que se fomenta la interactividad.

Gabriella infinita (2002) y Golpe de gracia (2006), del escritor Jaime Alejandro Rodríguez, son otras dos muestras de las posibilidades expresivas del medio. Gabriella infinita fue primero una novela (1994), después un hipertexto (1999) y finalmente un hipermedia. La versión hipermedial de Gabriella es el intento de generar una obra que contuviera la mejor solución para algunos de los potenciales hipertextuales y audiovisuales que contenía la versión en novela. Este paso del texto al hipertexto exigió una reconfiguración del texto original, así como el diseño de un nuevo recorrido narrativo, más ágil y verosímil, una mejor solución a las sugerencias audiovisuales, una interfaz altamente interactiva y el ensamblaje de los distintos elementos multimediales como audio, videos, animaciones e infografías.

Por contraste, Golpe de gracia se diseñó desde el comienzo como una pieza hipermedial interactiva, que combina texto, ilustración, audio, modelado, animación y programación, y narra la historia de un personaje que sufre una experiencia cercana a la muerte, situación que se utiliza como metáfora de la transición cultural contemporánea. El multimedia está compuesto por tres «mundos narrativos» - Cadáver exquisito, Línea mortal y Muerte digital-y cuatro "salas de profundización» - juegos, lectura, estudio, construcción-. Propone diversos grados de interacción que van desde tomar decisiones para realizar los recorridos hasta la construcción colectiva de texto, pasando por la participación en varios juegos interactivos.

A un nivel más global es posible dar cuenta de algunos ejemplos de sitios web que han desarrollado recursos para la narración digital con disposición o potencialidad para la interactividad participativa. Estos ejemplos constituyen un paisaje de los antecedentes y de las posibilidades de la narración digital colectiva.

Storyspace de Eastgate. Eastgate es tal vez uno de los portales más antiguos sobre producción y reflexión en torno al hipertexto. Desde el comienzo ofrece una herramienta para escritura hipertextual: el Storyspace, utilizada por algunos de los pioneros de la hiperficción -Joyce, Moultrouph, Bolter-. La herramienta ha evolucionado y ofrece ahora la posibilidad de publicar sus resultados fácilmente en la web. Aunque su diseño y filosofía están orientadas a la escritura de autor, puede ser usada para proyectos colectivos ${ }^{7}$.

7 Ver sitio de Storyspace en: http://www.eastgate.com/ storyspace/index.html 
Mapa interactivo de México DF. Este proyecto tiene una trayectoria bien interesante. Comienza como la digitalización de un antiguo mapa de la Ciudad de México del siglo xv, pasa por la exposición del archivo digital en museos, se desarrolla como performances interactivos en muestras de arte interactivo y culmina con la producción de una plataforma para internet donde son invitadas personas que quieran narrar, de distintas formas, historias sobre las calles y monumentos representados en el mapa. Constituye un interesante antecedente de las posibilidades de narrar colectivamente, aunque se encuentra limitado por dos condiciones: no es una plataforma abierta y la narración que se desarrolla es más una acumulación de «historias» por parte de los colaboradores que una acción colectiva. Su potencial, sin embargo, es muy importante por dos razones: su alta multimedialidad - hay textos, fotografías, videos-y el motivo mismo de «narrar el espacio» — en este caso, histórico-, es decir, de poblarlo con objetos digitales.

Wordtoys y Niño burbuja de Belén Gache ${ }^{8}$. Los ejercicios narrativos de Belén Gache tienen dos características muy importantes: están soportados por una base teórica muy sólida - la teoría de los mundos posibles aplicada a la literatura - y muestran una creativa exposición de motivos narrativos. Efectivamente, en Wordtoys podemos encontrar desde un inventario de las figuras literarias dedicadas a las mariposas hasta el sugerente idioma de los pájaros. Como narrativa digital explota muy bien el medio — animaciones, audio, hipertexto- y despliega una sensibilidad especial. En Niño burbuja, Belén ha propuesto un mecanismo de escritura mediante el weblog. En ambos resuena la posibilidad de lo colectivo, posibilidad que tal vez tenga sólo un límite tecnológico ${ }^{9}$. Wikinovela. Patricia Fernández y Santiago Pérez Isasi de la Universidad de Deusto -País Vasco- diseñaron y desarrollaron una estrategia bien coordinada para poner en marcha un proyecto de creación

8 Ver el sitio de Niño burbuja en: http://www.bubbleboy. findelmundo.com.ar/

9 Ver el sitio de Wordtoys en: http://www.findelmundo.com.ar/ wordtoys/index.htm hipertextual colectiva y multilingüe, abierto al público, que se anunció como "primera edición» limitada entre el 24 de abril de 2006 y el 24 de julio del mismo año. El objetivo central del proyecto radicaba en poner en escena distintos componentes lingüístico-literarios y de las tic aplicados al hecho narrativo. Los resultados fueron impresionantes y generaron una comunidad de escritores que periódicamente realizaban sus aportaciones desarrollando el argumento central y creando múltiples ramificaciones de las distintas versiones. Es tal vez el antecedente más importante del modo colectivo de narrar, pues además está completamente documentado.

Otros proyectos. Existen muchos otros sitios y propuestas que podrían completar los antecedentes de la narración colectiva. Un proyecto interesante es el llamado por Libro flotante ${ }^{10}$, una web que se ha creado para que sus usuarios «puedan aportar sus propios fragmentos de un libro que queda abierto para que cada versión apócrifa pueda considerarse parte de ese libro» (Tisselli, 2006). El proyecto promueve, pues, al estilo de las fans fictions, la escritura apócrifa, la oportunidad de incluir y crear nuevos fragmentos de una obra, escribir y reescribir los textos de un libro "desaparecido". Asimismo, tenemos el sitio Cibertextualidades ${ }^{11}$, del Centro de Investigación del Texto Informático y Cibercultura de la Universidad Fernando Pesoa, el cual constituye un ejemplo de plataforma "académica" y de actividad cibertextual que se encamina a la investigación y producción multimedial de carácter interartístico e interdisciplinario.

Finalmente, reseñamos la novela navegable o transmedia Bitácora a la deriva, libro que forma parte del proyecto "Plot28", considerado en el ámbito de la producción cultural y académica como uno de los más innovadores proyectos pioneros de narrativa transmedia. La novela expandida aparece firmada por Jaime Miñana, y no es para nada un libro

10 Ver en: http://www.libroflotante.net/intro.htm 11 Ver en: http://cibertextualidades.ufp.edu.pt/ 
de relatos convencional, pues a medida que se avanza en sus relatos se van encontrando puertas de entrada a experiencias que lo que hacen es ampliar el universo narrado. Twitter, Facebook, YouTube o Códigos QR llevan al lector-usuario por ese laberinto de relatos trasmediados que enriquecen y expanden la lectura a través del uso de un smartphone o una tableta. Leer esta novela modifica y cambia su sentido, pues el lector abandona por momentos las páginas de papel y se sumerge en entornos virtuales que amplían la noción de lectura que teníamos hasta ahora en las narrativas lineales y analógicas.

Vivimos inmersos en un mundo de imágenes, sonidos, símbolos, palabras, que modifican la perspectiva lineal y secuencial que teníamos del mundo. La facilidad para crear multimedias, distribuirlas y consumirlas convierte a los espectadores y a los usuarios en nuevos ejércitos de fans que expanden ese universo estético con sus aportaciones y prácticas postproductivas. En este sentido, la nueva escritura audiovisual, el streaming, es la forma de representación más importante del nuevo consumo audiovisual, potenciado por las herramientas Open Source de la web 2.0 y las redes sociales, y es ahí justamente donde se está tejiendo la más interesante y novedosa forma del transmedia storytelling y de una estética universal online.

En resumen, lo que está en proceso en la sociedad digital es una reorganización profunda de la manera de producir, crear y distribuir contenido cultural, una mutación que tiene que ver indudablemente con la facilidad tecnológica que tenemos a la mano y que perfila nuevos creadores amparados en el remix, el collage y los mashups, gracias a que hoy, a través de internet, es más fácil acceder a contenidos, manipularlos, reinventarlos y distribuirlos nuevamente por variadas plataformas de consumo, fundamentalmente audiovisuales, lo que está creando una especie de nomadismo estético, del que es difícil huir y mucho menos ignorar. De acuerdo a lo anterior, considero que estamos en un momento ideal para formar estudiantes para la producción editorial multimedial desde una mirada transmediática. La producción de textos es cada vez mayor en entornos digitales, contrapuesta a la impresión de estos en papel. Esta situación exige entender y desarrollar nuevas lógicas para la producción editorial y multimedial para estas nuevas generaciones de nativos digitales.

\section{Referencias}

Beelen, P. (2006). Publicidad 2.0. Lo que deberían saber quienes trabajan en publicidad, marketing y medios sobre las tecnologías que están revolucionando su rubro. Recuperado de http://ru.dgb.uas.edu.mx:8080/jspui/ bitstream/DGB_UAS/153/1/Publicidad20.pdf

Bringué, X., y Sádaba, C. (Coords.). (2008). La Generación Interactiva en Iberoamérica. Madrid: Fundación Telefónica/Ariel.

Castells, M. (2002). La galaxia internet. Barcelona: Random House Mondadori.

Cobo, C., y Pardo, H. (2007). Planeta web 2.0. Inteligencia colectiva o medios fast food. Barcelona / México: Grup de Recerca d'Interaccions Digitals, Universitat de Vic.

De Kerckchove, D. (1999). Inteligencias en conexión. Barcelona: Editorial Gedisa.

Freire, J. (2007). Los retos y oportunidades de la web 2.0 para las universidades. En R. Jiménez, \& F. Polo, La gran guía de los blogs 2008 (pp. 82-90). Barcelona: El Cobre Ediciones.

Hernández-Pérez, T. (23 de febrero de 2011). Informe Pew sobre el uso de Internet por generaciones (2010). Recuperado de http://www.ub.edu/blokdebid/es/content/ informe-pew-sobre-el-uso-de-internet-porgeneraciones- 2010 
Jenkins, H. (2008). Convergence culture: La cultura de la convergencia de los medios de comunicación. Barcelona: Paidós.

Kerckhove, D. (1999). Inteligencias en Conexión. Hacia una sociedad de la Web. Barcelona: Gedisa Editorial.

Landow, G. (1995). Ipertexto, la convergencia de la teoría crítica contemporánea y la tecnología. Barcelona: Paidós.

Lévy, P. (2007). Cibercultura. Informe al Consejo de Europa. Iztapalapa: Anthropos Editorial / Universidad Autónoma Metropolitana.

Moraes, D. (coord.). (2005). Por Otra comunicación. Los media, globalización cultural y poder. Barcelona: Icaria Editorial / Intermón Oxfam.

Pérez, J. (2011). Comunidades de práctica como sistemas emergentes de aprendizaje. En J. Rodríguez, Narratopedia. Reflexiones sobre narrativa digital, creación colectiva y cibercultura (pp. 255-269). Bogotá: Editorial Pontificia Universidad Javeriana.

Piscitelli, A. (2005). Internet: la imprenta del siglo $X X I$. Barcelona: Editorial Gedisa.
Piscitelli, A. (2009). Nativos digitales. Dieta cognitiva, inteligencia colectiva y arquitecturas de la participación. Buenos Aires: Santillana.

Reig Hernández, D. (2012). Socionomía. ¿Vas a perderte la revolución social? Barcelona: Deusto S.A. Ediciones.

Reig, D. (1 de octubre de 2011). TIC, TAC, TEP y el 15 de octubre. Recuperado de http://www.dreig. eu/caparazon/2011/10/11/tic-tac-tep/

Rheingold, H. (2004). Multitudes inteligentes. La próxima revolución social. Barcelona: Gedisa.

Scolari, C. (2008). Hipermediaciones: elementos para una teoría de la comunicación digital interactiva. Barcelona: Gedisa.

Scolari, C. (2013). Narrativas transmedia: cuando todos los medios cuentan. Barcelona: Deusto S.A. Ediciones.

Toffler, A. (1980). La tercera ola. Bogotá: Plaza \& Janes. 